\title{
Biodegradable Polymer Scaffolds with Well-Defined Interconnected Spherical Pore Network
}

\author{
PETER X. MA, Ph.D. ${ }^{1-3}$ and JI-WON CHOI, M.S. ${ }^{2}$
}

\begin{abstract}
Scaffolding plays pivotal role in tissue engineering. In this work, a novel processing technique has been developed to create three-dimensional biodegradable polymer scaffolds with well-controlled interconnected spherical pores. Paraffin spheres were fabricated with a dispersion method, and were bonded together through a heat treatment to form a three-dimensional assembly in a mold. Biodegradable polymers such as PLLA and PLGA were dissolved in a solvent and cast onto the paraffin sphere assembly. After dissolving the paraffin, a porous polymer scaffold was formed. The fabrication parameters were studied in relation to the pore shape, interpore connectivity, pore wall morphology, and mechanical properties of the polymer scaffolds. The compressive modulus of the scaffolds decreased with increasing porosity. Longer heat treatment time of the paraffin spheres resulted in larger openings between the pores of the scaffolds. Foams of smaller pore size $(100-200 \mu \mathrm{m})$ resulted in significantly lower compressive modulus than that of larger pore sizes (250-350 or 420-500 $\mu \mathrm{m})$. The PLLA foams had a skeletal structure consisting of small platelets, whereas PLGA foams had homogeneous skeletal structure. The new processing technique can tailor the polymer scaffolds for a variety of potential tissue engineering applications because of the wellcontrolled architecture, interpore connectivity, and mechanical properties.
\end{abstract}

\section{INTRODUCTION}

$\mathbf{E}$ NGINEERING TISSUES AND ORGANS with mammalian cells and a scaffolding material is a new approach in contrast to the use of harvested tissues and organs. ${ }^{1}$ In the tissue engineering approach, the scaffold plays a pivotal role in cell seeding, proliferation, and new tissue formation in three dimensions. ${ }^{2-5}$ Biodegradable polymers have been attractive candidates for scaffolding materials because they degrade as the new tissues are formed, eventually leaving nothing foreign to the body. ${ }^{6} \mathrm{~A}$ few techniques such as salt leaching, ${ }^{7-9}$ fibrous fabric processing, ${ }^{6,10}$ gas foaming, ${ }^{11}$ emulsion freeze-drying, ${ }^{12}$ three-dimensional printing, ${ }^{13}$ and phase separation ${ }^{5,14-17}$ have been developed to generate highly porous polymer scaffolds for tissue engineering. These scaffolds have shown great promise in the research of engineering a variety of tissues. ${ }^{18-29}$ However, to engineer clinically useful tissues and organs is still a challenge. The understanding of the principles of scaffolding is far from satisfactory, and the "ideal" scaffolds are yet to be developed.

${ }^{1}$ Department of Biologic and Material Sciences, ${ }^{2}$ Macromolecular Science and Engineering Center, and ${ }^{3}$ Department of Biomedical Engineering, University of Michigan, Ann Arbor, Michigan. 
Pore size, porosity, and surface area (surface-to-volume ratio) are widely recognized as important parameters for a scaffold for tissue engineering. ${ }^{5,8,30}$ Other architectural features such as pore shape, pore wall morphology, and interconnectivity between pores of the scaffolding materials are also suggested to be important for cell seeding, migration, growth, mass transport, gene expression, and new tissue formation in three dimensions. ${ }^{5,29,31}$ This paper reports on the development of a novel technique to generate well-controlled interconnected spherical or partially spherical (hollow shell or partial shell) macropores in biodegradable polymer scaffolds.

\section{EXPERIMENTAL PROCEDURES}

\section{Materials}

Poly(lactide) (PLLA) and poly(lactide-co-glycolide) (85/15) (PLGA85/15) were purchased from Boehringer Ingelheim (Ingelheim, Germany). Poly(vinyl alcohol) (PVA) with a molecular weight of 25,000 and paraffin with a melting point of $53-57^{\circ} \mathrm{C}$ were purchased from Fisher Scientific (Pittsburgh, PA). Pyridine, hexane, and cyclohexane were purchased from Aldrich (Milwaukee, WI). U.S. standard sieves (100 $\mu \mathrm{m}, 250 \mu \mathrm{m}, 350 \mu \mathrm{m}, 420 \mu \mathrm{m}$, and $500 \mu \mathrm{m}$ ) were purchased from Newark Wire Cloth Company (Newark, $\mathrm{NJ})$.

\section{Preparation of paraffin spheres}

PVA was dissolved in distilled water to make a $0.5 \%(\mathrm{~g} / \mathrm{mL})$ solution. The PVA solution was heated to $60-70^{\circ} \mathrm{C}$. Paraffin was heated to melt in a glass vial on a hot plate and was added to the PVA solution. The mixture was vigorously stirred with a magnetic stirring bar with a stirring setting of 6-8 on a hot plate (Fisher Scientific, Pittsburgh, PA). Ice-cold water was poured into the stirred suspension to solidify the paraffin spheres. The suspension containing the paraffin spheres was then poured into a sieve with an opening of $100 \mu \mathrm{m}$ to sift out the paraffin particles smaller than $100 \mu \mathrm{m}$. The paraffin spheres were then washed with distilled water for three to five times to remove the residual PVA. After being dried in air for 1 week, the spheres were sifted with U.S. standard sieve series $(100 \mu \mathrm{m}, 250 \mu \mathrm{m}, 350 \mu \mathrm{m}, 420 \mu \mathrm{m}$, and $500 \mu \mathrm{m})$ to separate them into different size ranges. The paraffin spheres with the desired sizes were collected and stored in a desiccator until use.

\section{Preparation of polymer foam}

The paraffin spheres $(0.5 \pm 0.05 \mathrm{~g})$ were added in a Teflon mold (cylindrical vial with a diameter of $18 \mathrm{~mm}$ ). The top surface of the paraffin spheres was leveled by tapping the mold on a leveled flat metal plate with three adjustable legs. The mold containing paraffin spheres was then carefully moved into an oven (preheated to $37^{\circ} \mathrm{C}$ ), kept for 20 min unless indicated otherwise, and then cooled down to room temperature. A chosen polymer was dissolved in pyridine to prepare a solution of a desired concentration. Then $0.40 \mathrm{~mL}$ of the polymer solution was cast onto the paraffin sphere assembly drop by drop. The mold containing the paraffin sphere assembly and the polymer solution was first maintained under low vacuum (an air pressure of $60 \mathrm{mmHg}$ ) to remove the air trapped inside the paraffin sphere assembly. Trapped air appeared as bubbles on the top surface. When no more bubbles were observed, a high vacuum (an air pressure $<0.5 \mathrm{mmHg}$ ) was used to evaporate the solvent for 2 (PLLA) or 7 days (copolymers). Additional casting and vacuum-drying steps were repeated to produce foams with higher polymer contents (lower porosity).

The dried paraffin/polymer discs were removed from the Teflon mold, and the top layer was cut away with a razor blade to obtain a flat surface. The discs were immersed in $200 \mathrm{~mL}$ of hexane to dissolve the paraffin at room temperature for 2 days. The hexane was changed three times a day. The hexane was then exchanged with cyclohexane and the discs were frozen in a freezer $\left(-20^{\circ} \mathrm{C}\right)$ for more than $6 \mathrm{~h}$. The frozen foams were freeze-dried in an ice bath for 2 days to remove cyclohexane and they were further dried at room temperature under vacuum for 1 week to remove the solvent completely. The foams were kept in a desiccator until characterization. 


\section{SPHERICAL PORE SCAFFOLDS}

\section{Characterization}

The density and the porosity of the foams were determined by measuring the dimensions and the mass of the foam. ${ }^{5}$ The skeletal density of the foam, $\rho$, was calculated as:

$$
\rho=\frac{4}{\pi} \frac{m}{d^{2} h}
$$

where $m$ was the mass, $d$ was the diameter, and $h$ was the thickness of the foam. The porosity, $\epsilon$, was calculated as:

$$
\epsilon=1-\frac{\rho}{\rho_{P}}
$$

where $\rho_{P}$ is the density of the polymer. For PLLA foam, $\rho_{P}$ was determined by:

$$
\rho_{P}=\overline{\frac{\left(1-X_{c}\right)}{\rho_{a}}+\frac{X_{c}}{\rho_{c}}}
$$

where $X_{c}$ was the crystallinity of the polymer, $\rho_{a}$ was the density of the amorphous region $(1.25 \mathrm{~g} / \mathrm{mL})$, and $\rho_{c}$ was the density of the crystalline region $(1.29 \mathrm{~g} / \mathrm{mL}) . X_{C}$ was given by

$$
X_{c}=\frac{\Delta H_{m}}{\Delta H_{m}^{o}}
$$

where $\Delta H_{m}$ was the enthalpy of melting measured with a differential scanning calorimeter (DSC) and $\Delta H_{m}^{o}$ was the enthalpy of melting for $100 \%$ crystalline polymer $(203.4 \mathrm{~J} / \mathrm{g}){ }^{5}$

Scanning electron microscopy (SEM) (S-3200N, Hitachi, Japan) was used at $5 \mathrm{kV}$ to examine the morphology. In sample preparation, paraffin/polymer specimens were cut into halves with a razor blade before the paraffin was leached out. The paraffin assembly provided the specimens with enough strength to maintain the morphological structure during the cutting. The paraffin was then leached out with hexane and cyclohexane to reveal the porous morphology. The prepared foams were coated with gold using a sputter coater (Desk-II, Denton vacuum Inc.). The gas pressure, the current and the coating time were 50 mtorr, $40 \mathrm{~mA}$, and $200 \mathrm{~s}$, respectively.

The overall three-dimensional arrangement of the pores inside the foam was studied with optical microscopy (Nikon, Model SMZ-2T). The sample was placed on a semitransparent stage and the light source was below the foam so that the pores were the lighter areas on the image due to the higher transmittance of light.

The compressive modulus values of the foams were measured with an Instron 4502 mechanical tester (Instron Co., Canton, Massachusetts). The specimens were porous discs $(\sim 17 \mathrm{~mm}$ in diameter and $\sim 3 \mathrm{~mm}$ in thickness). The cross-head speed was $0.5 \mathrm{~mm} / \mathrm{min}$. The modulus was determined with the initial slope of the stress-strain curve (strain range, 3-8\%). When the moduli of different foams were compared, a onetail Student $t$-test (assuming unequal variances) was performed to determine the statistical significance $(p$ values $<0.05$ were considered significant).

\section{RESULTS}

Mechanical stirring and subsequent quenching of the paraffin suspension with ice water produced uniform spherical paraffin particles (Fig. 1A,B). The size of the spheres was controlled in the range of 100-500 $\mu \mathrm{m}$, with the maximum yield at around $300 \mu \mathrm{m}$. The stirring rate and the concentration of the PVA solution were important in controlling the size distribution and the shape of the spheres. Faster stirring rate and higher concentration of the PVA solution resulted in smaller particles with a uniform spherical shape, whereas a slower stirring rate and lower PVA concentration resulted in larger particles, with which a cer- 
A

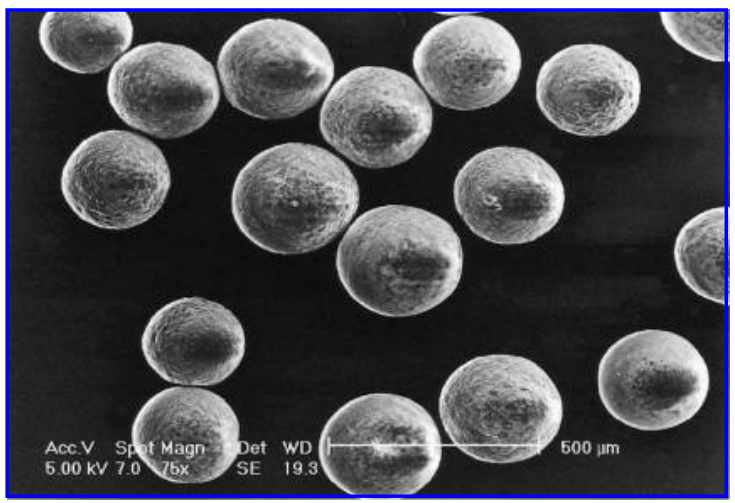

C

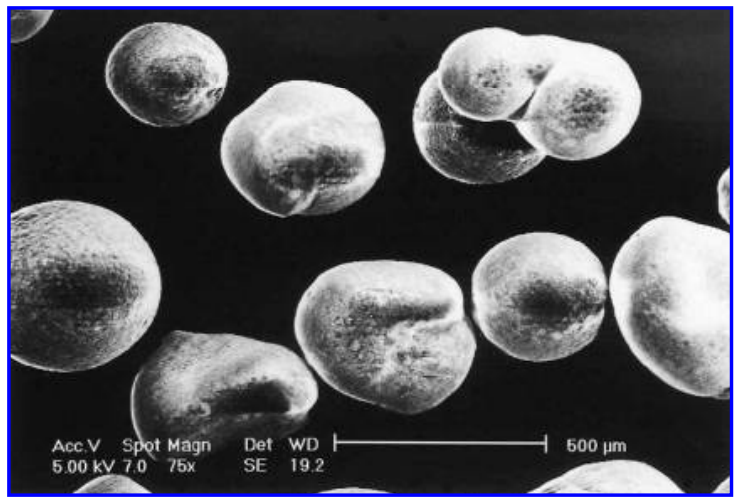

B

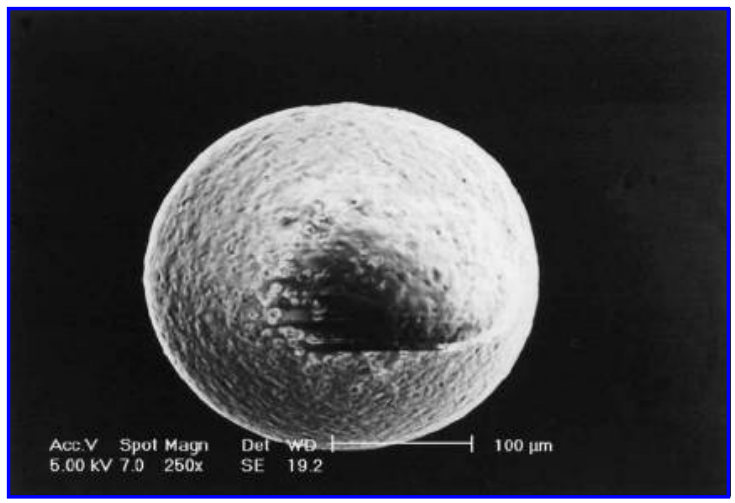

FIG. 1. SEM micrographs of paraffin particles made with melt paraffin in a PVA solution as described in the experimental section. $(\mathbf{A}) \times 75$, spherical shape. $(\mathbf{B}) \times 250$, spherical shape. $(\mathbf{C}) \times 75$, asymmetric shapes.

tain portion of nonspherical particles was found (Fig. 1C). The generation of these undesirable shapes was suppressed by controlling the stirring rate and the concentration of the PVA solution.

The heat treatment at $37^{\circ} \mathrm{C}$ produced firm bonding between the paraffin spheres to form a three-dimensional assembly (the paraffin spheres began to deform at $33-34^{\circ} \mathrm{C}$ ). This treatment ensured the complete connectivity of the pores of the final foam structure after the paraffin was leached out with a solvent/solvents. Because all the spheres were bonded together, no closed pores were generated when the paraffin assembly was removed, as demonstrated in the optical microscopic image of the foam (Fig. 2). The polymer was PLLA, the paraffin spheres were $250-420 \mu \mathrm{m}$ in size, and the porosity was about $96 \%$. The polymer skeleton of the foam appeared dark due to the low transmittance of light, whereas the pores appeared light due to the high transmittance of light. The bright areas were the holes connecting the pores. Any closed pore with trapped paraffin would have appeared as a black circle (in the darkest contrast) because of the lowest transmittance of light. However, no black circles were observed, suggesting that all the pores were open and well connected. Another benefit of the heat treatment was the mechanical stability of the resulting paraffin assembly in contrast to the loose paraffin spheres. The loose paraffin spheres could be easily disturbed by a small droplet of polymer solution in the casting step, while the spatial relationship among the bonded paraffin spheres were maintained in the casting process.

PLLA/pyridine solutions of several different concentrations $(8 \%, 10 \%, 12 \%, 15 \%$, and 18\%) were tested to find an optimal casting concentration at room temperature. It was known that random packing densities of monodisperse spheres were $60-65 \% .^{32}$ The volume fraction of the free space of the packed paraffin spheres, therefore, was approximately $35-40 \%$, neglecting the volume decrease resulted from the bonding between paraffin spheres. The volume of each disc of bonded paraffin spheres was about $0.85 \mathrm{~cm}^{3}$ and thus a volume fraction of $40 \%$ corresponded to $0.34 \mathrm{~mL}$. In our experiments, a $0.40-\mathrm{mL}$ polymer solution was used for each specimen to cover the paraffin disc completely. Different polymer concentrations resulted in 


\section{SPHERICAL PORE SCAFFOLDS}

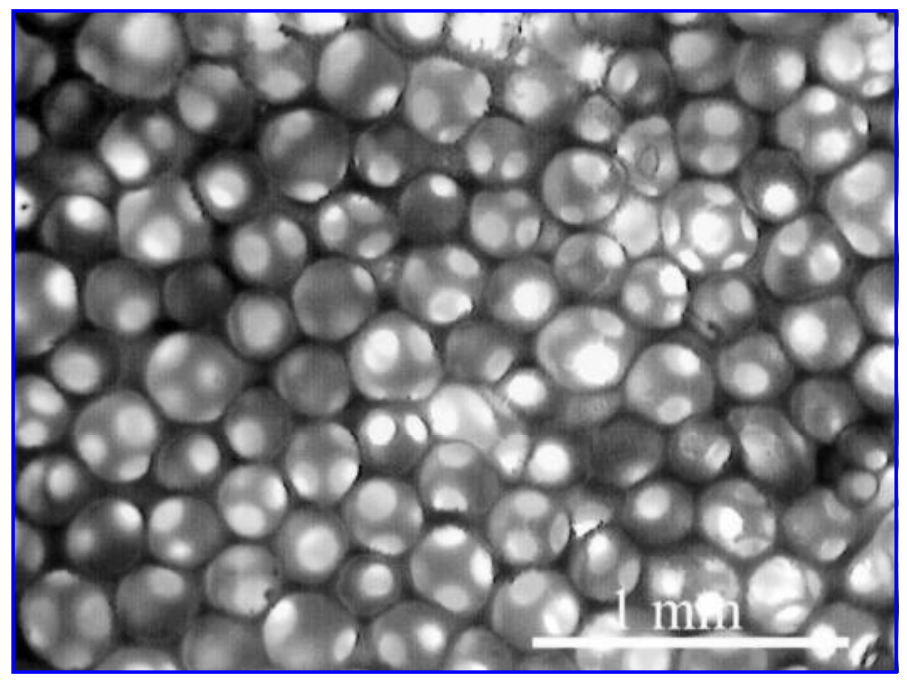

FIG. 2. Optical micrograph of PLLA foam prepared with paraffin spheres with a size range of $250-420 \mu \mathrm{m}$ and one casting step $(\times 40)$.

different porosities (Table 1). In general, a polymer solution of higher concentration produced a denser structure. However, the mechanical properties did not necessarily increase with increasing density of the foams. Properties of the polymer foam made from $8 \%$ PLLA solution were too weak to measure. Highly concentrated polymer solutions, such as $15 \%$ or $18 \%$, also resulted in relative weak foam formation probably because the high viscosity of the polymer solutions impeded their flow into the interstices between the spheres. As a result, the polymer was not evenly distributed in the disc and weak areas were formed. The concentration of $12 \%(\mathrm{~g} / \mathrm{mL})$ was found to be suitable for casting at room temperature, and this concentration was used for the rest of the study.

Because a porosity of lower than $96 \%$ was not achievable with only a single casting of $12 \%$ solution, several casting steps had to be repeated to form the denser foams with higher modulus (Fig. 3). For these homogeneous foams, the modulus increased with increasing foam density (decreasing porosity) in a monotonous way. At a porosity of $94.5 \%$, a modulus of about $300 \mathrm{kPa}$ was obtained.

Morphologies of these foams were studied with SEM (Fig. 4). The PLLA foam had a porosity of $95 \%$ and the original paraffin spheres were $250-420 \mu \mathrm{m}$ in size. The pores retained the shapes of the original paraffin spheres and were well connected. The diameters of the cross sections of the individual pores appeared different from each other because the cutting surface intersected the pores at different positions. The openings between the pores were circular in shape and were similar in size. The macropore network was the replica of the surface of the bonded paraffin spheres. In other words, the hollow spherical shell network formed the continuous skeleton of the foam, and the pores were interconnected through the openings formed by the bonding areas of the paraffin spheres. The surface morphology of the pore wall was very similar to that of the new surface exposed by cutting, which indicated that the entire polymer skeleton of the foam

Table 1. Density, Porosity, and Compressive Modulus of Plla Foams

\begin{tabular}{lcccc}
\hline $\begin{array}{l}\text { Polymer } \\
\text { concentration }\end{array}$ & $\begin{array}{c}\text { Paraffin } \\
\text { sphere }\end{array}$ & $\begin{array}{c}\text { Density } \\
\left(\mathrm{g} / \mathrm{cm}^{3}\right)\end{array}$ & $\begin{array}{c}\text { Porosity } \\
(\%)\end{array}$ & $\begin{array}{c}\text { Compressive } \\
\text { modulus }(\mathrm{kPa})\end{array}$ \\
\hline $10 \%(\mathrm{wt} / \mathrm{vol})$ & $250-420 \mu \mathrm{m}$ & $0.032 \pm 0.002$ & $96.8 \pm 0.2$ & $23.7 \pm 18.5$ \\
$12 \%(\mathrm{wt} / \mathrm{vol})$ & $250-420 \mu \mathrm{m}$ & $0.039 \pm 0.003$ & $96.1 \pm 0.3$ & $81.8 \pm 17.1$ \\
$15 \%(\mathrm{wt} / \mathrm{vol})$ & $250-420 \mu \mathrm{m}$ & $0.048 \pm 0.004$ & $95.2 \pm 0.4$ & $46.8 \pm 21.3$ \\
$18 \%(\mathrm{wt} / \mathrm{vol})$ & $250-420 \mu \mathrm{m}$ & $0.042 \pm 0.001$ & $95.8 \pm 0.1$ & $50.8 \pm 13.2$ \\
\hline
\end{tabular}




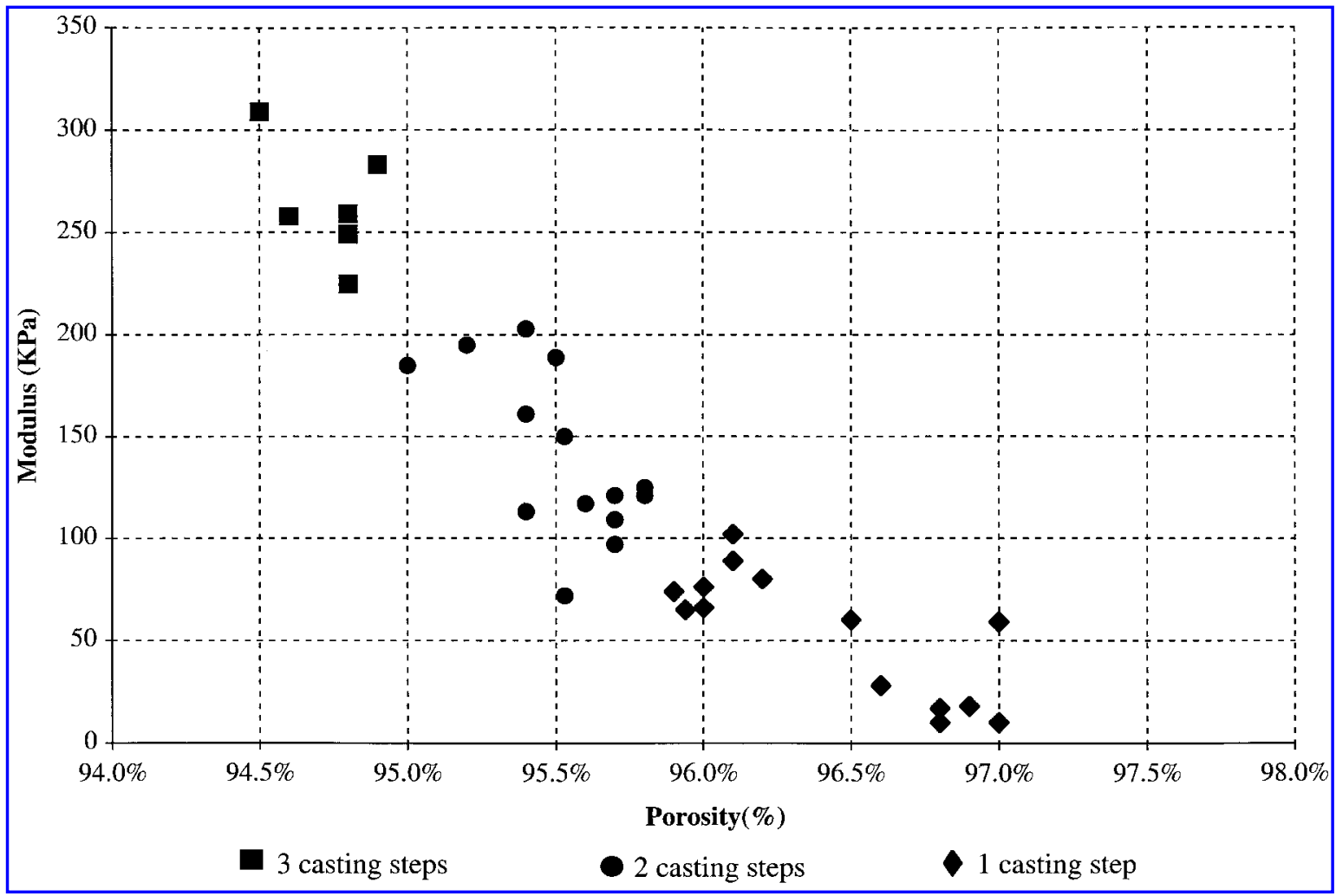

FIG. 3. Modulus versus porosity of PLLA foams prepared with paraffin spheres with a size range of $250-420 \mu \mathrm{m}$ and different numbers of casting steps.

was uniform in morphology. The polymer skeleton was composed of platelets and irregular micropores between them, similar to the morphology previously observed for PLLA foams prepared without paraffin spheres from different solvent systems at room temperature. ${ }^{5}$ The microporous walls of the macropores could be beneficial to the local mass transport in a scaffold for tissue engineering.

Heat treatment at $37^{\circ} \mathrm{C}$ for $20 \mathrm{~min}$ generated the moderate size of the opening between the pores. It was expected that the size of these openings could be controlled by adjusting the time and the temperature of the heat treatment. To examine the effect of the time of heat treatment on the size of the openings between macropores, paraffin spheres of narrow size distribution $(250-350 \mu \mathrm{m})$ were treated at $37^{\circ} \mathrm{C}$ for 20 and 80 min, respectively. The longer time of the heat treatment formed larger bonding areas between the paraffin spheres and resulted in larger openings between the macropores of the polymer foam (Fig. 5).

The mechanical properties of the polymer foams were affected by the pore size (Fig. 6). The PLLA foams prepared with three different sizes of paraffin spheres were controlled at the same porosity level (94.5\%). When the paraffin spheres with the size of 100-200 $\mu \mathrm{m}$ were used, the modulus of the formed foam was statistically lower than that of the foams prepared with larger paraffin spheres. The difference between the two larger pore sizes was not statistically significant. The lower modulus of the foams prepared with the smaller paraffin spheres might have resulted from the heterogeneity of polymer distribution because the polymer solution might penetrate with more difficulty into the smaller interstices between smaller spheres, resulting in formation of irregular large pore defects and/or thin pore walls.

Foams were also prepared using PLGA85/15 copolymer (Fig. 7). Paraffin spheres of the sizes of 420-500 $\mu \mathrm{m}$ were used and the concentration of the polymer solution was $12 \%$. Unlike in PLLA foams, neither platelets nor micropores were found either on the surface of the pore wall or in the interior of the polymer skeleton of the foams. The entire structure was homogeneous and well connected. This could stem from the difference in the physical structure of the two polymers. The PLGA85/15 copolymer was amorphous 

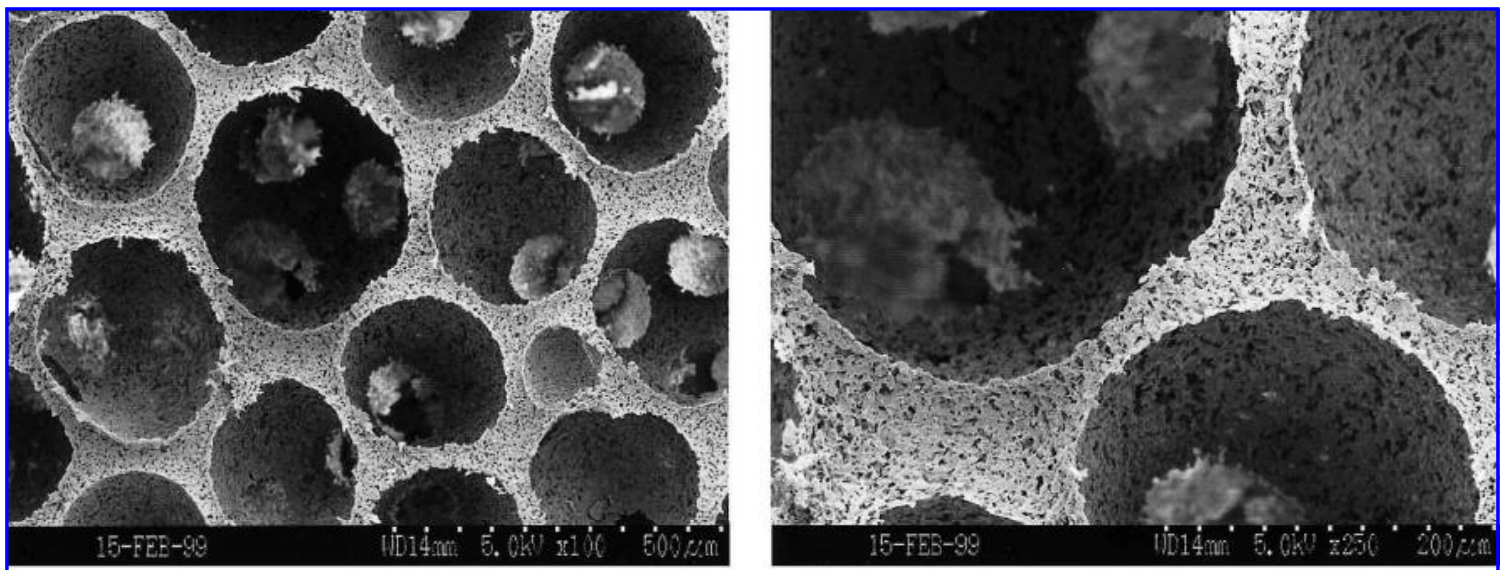

C

D
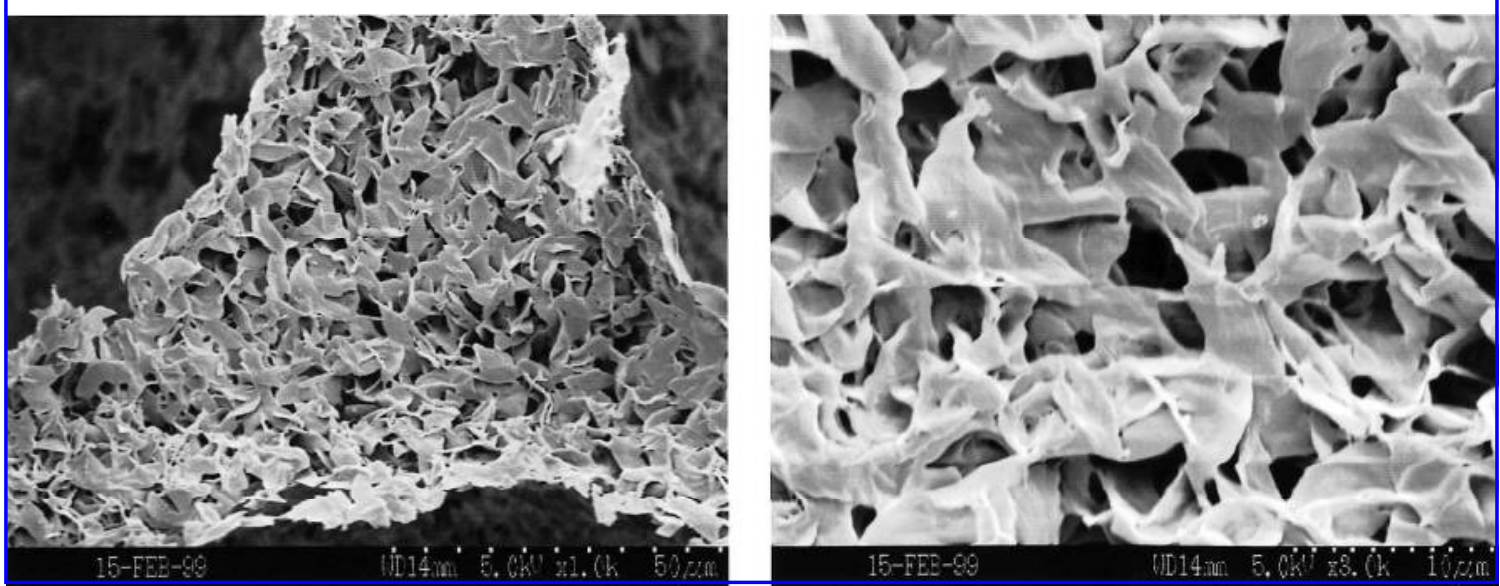

FIG. 4. SEM micrographs of PLLA foams prepared with paraffin spheres with a size range of $250-420 \mu \mathrm{m}$ and two casting steps. (A) $\times 100 ;(\mathbf{B}) \times 250 ;(\mathbf{C}) \times 1 \mathrm{k} ;(\mathbf{D}) \times 3 \mathrm{k}$.

A

B

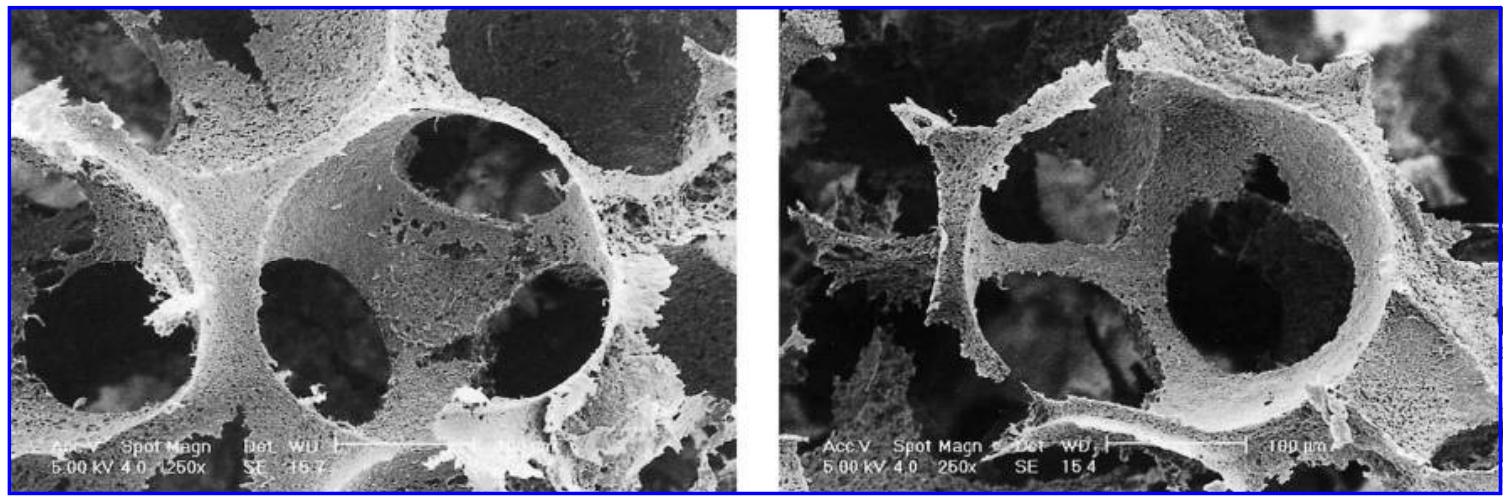

FIG. 5. SEM micrographs of PLLA foams prepared with paraffin spheres with a size range of 250-350 $\mu \mathrm{m}$ and one casting step $(\times 250)$. The paraffin spheres were bonded together through a heat treatment at $37^{\circ} \mathrm{C}$ for different time periods. (A) Heat treatment time, 20 min. (B) Heat treatment time, 80 min. 
whereas PLLA was semicrystalline. The platelet structure could be formed through a nucleation and crystal growth process from a crystalline polymer PLLA. ${ }^{5}$ Amorphous polymer PLGA85/15 did not crystallize, therefore only a smoother layer of polymer was deposited on the paraffin spheres. At a high porosity, polymer only covered the connecting areas between the original paraffin spheres (larger connecting lines between spheres or the necklines of the bonding areas), likely due to the surface tension effect of the polymer solution (Fig. 7A,B). The overall interconnected pore architecture was demonstrated in an edge view of the foam (Fig. 7C). At a lower porosity, the open surface of the paraffin spheres was covered more to form a more continuous hollow shell morphology (Fig. 7D).

\section{DISCUSSION}

Scaffolding is a critical component in tissue engineering because it provides the three-dimensional clues for cell seeding, migration, growth, and the new tissue formation. Synthetic polymers such as polylactide, polyglycolide, and poly(lactide-co-glycolide) are biodegradable and biocompatible, and are FDA approved for certain clinical applications such as resorbable sutures. Therefore, these polymers are widely exploited as scaffolding materials for tissue engineering. Salt-leaching is a very popular technique to fabricate scaffolds from a variety of polymers, and is well recorded in the literature. ${ }^{7,8}$ In this technique, the polymer (usually in the solution form) is first mixed with $\mathrm{NaCl}$ salt crystals to form a polymer/salt composite material (after solvent evaporation). The salt is then leached out with water to form the pores of the polymer foam. The pore size can be controlled by the size of the salt crystals, and the porosity can be controlled by the salt/polymer ratio. However, with the salt-leaching technique, the pore shape is limited to the cubic crystal shape of the $\mathrm{NaCl}$ salt, and, more disadvantageously, the interpore connectivity is not controlled. To obtain a spherical pore shape, a technique including compression molding of gelatin spheres and poly-

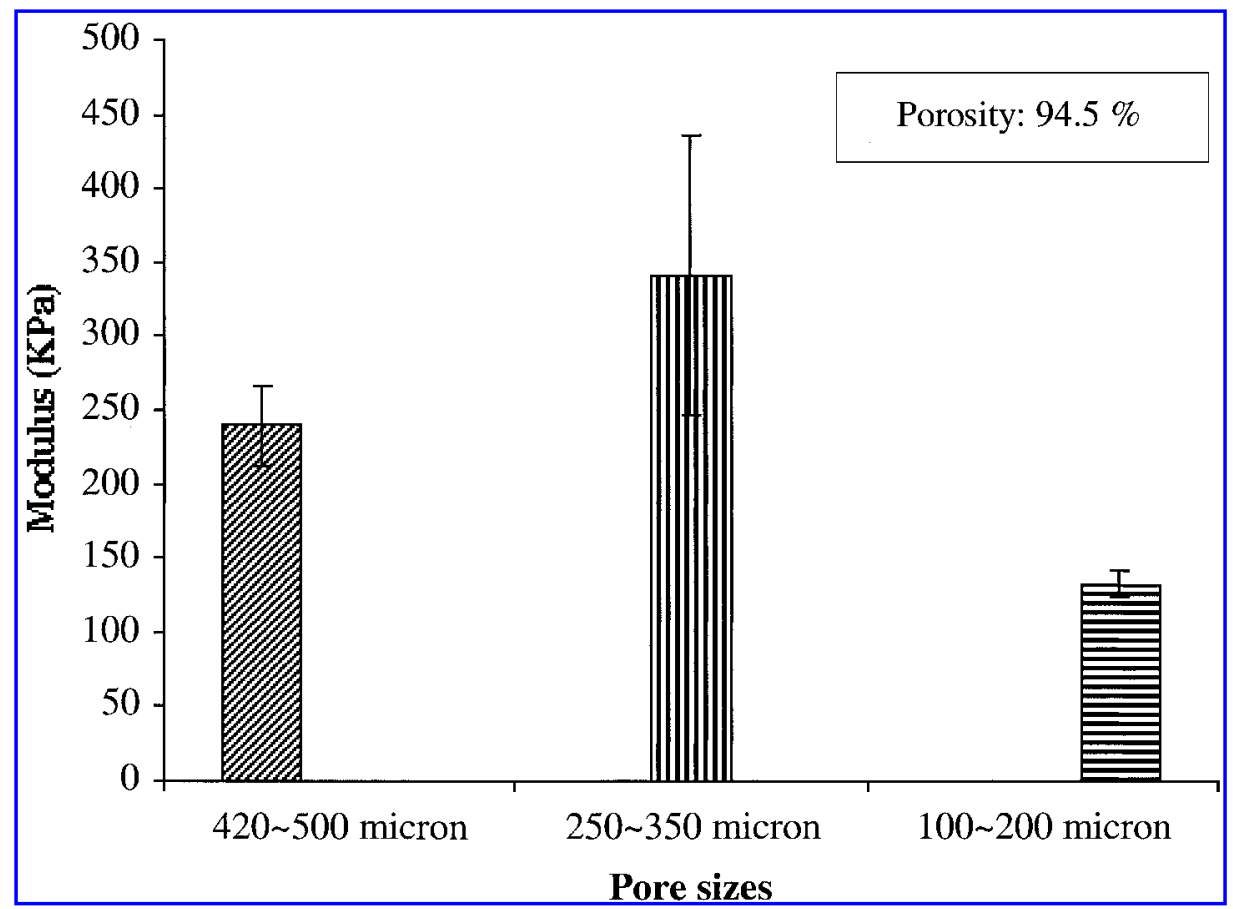

FIG. 6. Pore size effect on the compressive modulus of PLLA foam with three casting steps (porosity, 94.5\%). The difference in modulus between the foams of a pore size range of $420-500 \mu \mathrm{m}$ and $250-350 \mu \mathrm{m}$ is not statistically significant $(p=0.357)$. The difference in modulus between the foams of a pore size range of $420-500 \mu \mathrm{m}$ and $100-200$ $\mu \mathrm{m}$, and that between foams of a pore size range of 250-350 $\mu \mathrm{m}$ and 100-200 $\mu \mathrm{m}$ are statistically significant $(p=$ 0.008 and 0.032 , respectively). 
A

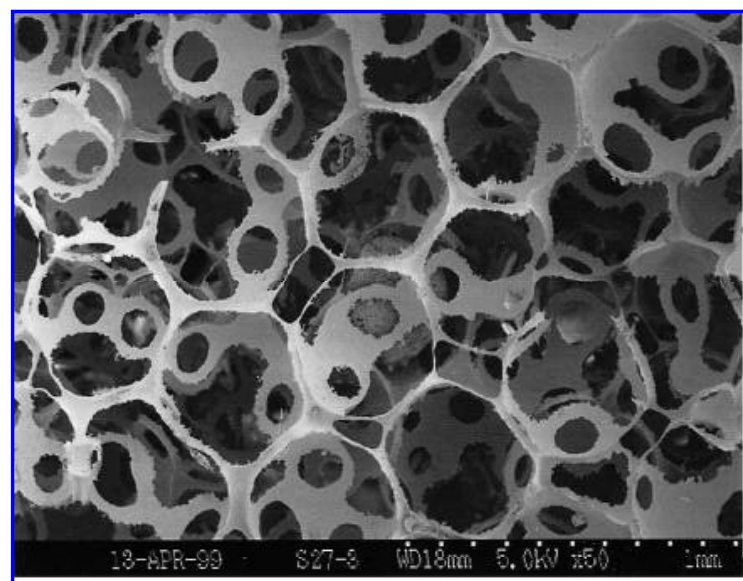

C

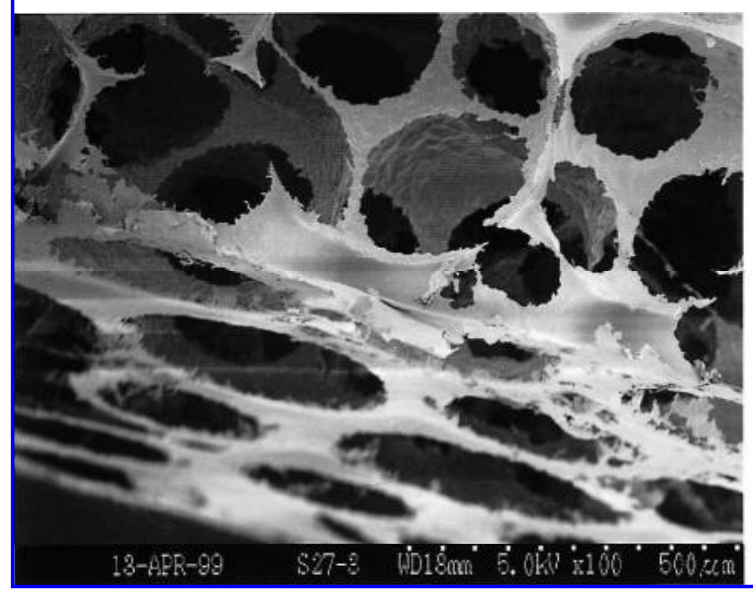

B

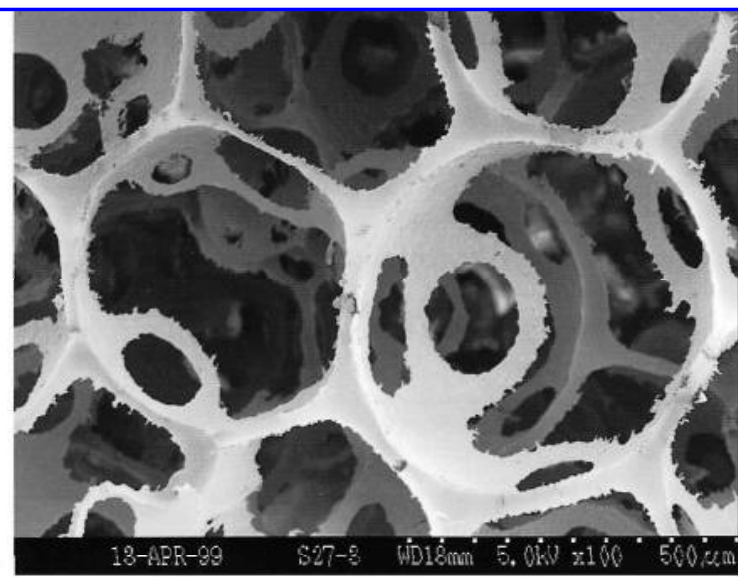

D

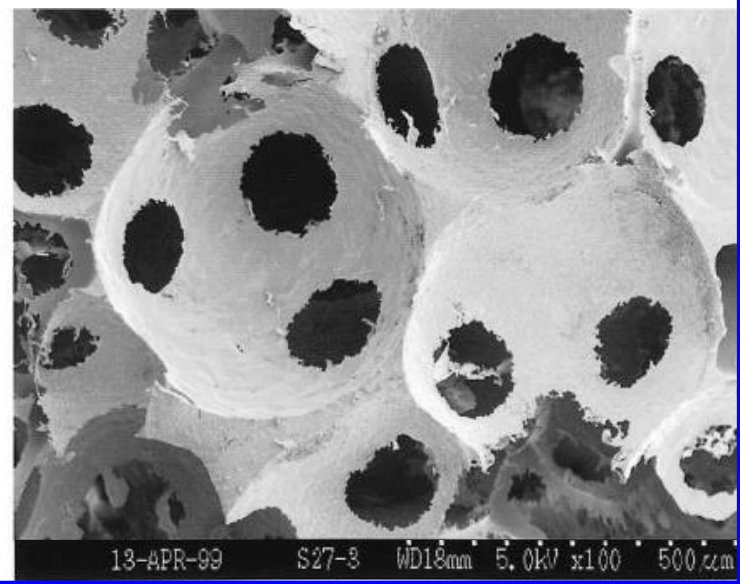

FIG. 7. SEM micrographs of PLGA foams prepared with paraffin spheres with a size range of 420-500 $\mu \mathrm{m}$. (A) One casting step, $\times 50$. (B) One casting step, $\times 100$. (C) One casting step, $\times 100$, an edge view of the foam. (D) Two casting steps, $\times 100$.

mer powder, and subsequent leaching of the gelatin spheres with water has been reported. ${ }^{4}$ However, that technique is limited to the generation of polymer foams with relatively low porosity (up to around $70 \%$ ). The interpore connectivity is not well controlled, and residual gelatin in the foams has been reported. ${ }^{4}$

In this work, we have fabricated paraffin spheres as a pore-generating material (porogen) to create spherical pore shape with well-controlled interpore connectivity in the biodegradable polymer foams. The control of the porosity and the pore size was demonstrated by changing the concentration of the polymer solution, the number of casting steps, and the size of the paraffin spheres. Porosity higher than $95 \%$ was easily achieved. Furthermore, we have developed a technique to bond these paraffin spheres together to stabilize the structure and, more importantly, to ensure the creation of an interconnected pore network in the polymer foam. We have also demonstrated that the bonding areas between paraffin spheres can be controlled to vary the size of the openings between the spherical pores, which can be very important in controlling cell seeding and distribution in the scaffolds. The processability of the paraffin can also be used to generate other geometrical components to be assembled into more complex structures for architecturally complex scaffolding formation, as we have demonstrated with sugar porogen. ${ }^{31}$ The macroporous architectural design can also be used to improve mass transport and neovasculature formation when implanted in vivo. 
The macroporous architectural design can be used to vary the flow pattern of the tissue culture medium in these scaffolds in bioreactor cultures and to mediate the fluid mechanical stimulation to engineered tissue constructs. We have further demonstrated that the foam architecture and pore wall structure (platelet like or continuous) are dependent on the polymer (especially the crystallizability) and the polymer concentration used. In addition, the paraffin sphere assembly can be dissolved in some organic solvents (nonsolvents of the polymer) so that certain water-soluble polymers can be involved in the scaffolding materials with this technique, which is important in improving the hydrophilicity of the scaffolding materials when desired.

There are also several advantages in the new fabrication methods. First, there is no sophisticated equipment requirement compared to the textile technology, free-forming, three-dimensional printing, or lithography. Second, the new scaffolding has a homogeneous foam skeleton (either platelet-like or continuous, depending on the crystallizability of the polymer), which is not easily achievable with free-forming, three-dimensional printing or lithography because of their "pixel assembly" nature. Third, the interpore connectivity and the size of the opening between pores are well controlled by the heat treatment process of the paraffin spheres. Fourth, the scaffold can be directly fabricated into a specific anatomical shape with a mold. Fifth, the process can be easily expanded or automated for large-scale production. In conclusion, the new processing technique can tailor the polymer foams for a variety of potential tissue engineering and other biomedical applications because of the well-controlled nature in architecture, interpore connectivity, and physical and mechanical properties.

\section{ACKNOWLEDGMENTS}

The authors acknowledge funding from the Whitaker Foundation, DuPont Young Professor Award, and Center for Biomedical Engineering Research at the University of Michigan. The authors thank Charles McLaren for his contribution during a summer research project.

\section{REFERENCES}

1. Langer, R.S., and Vacanti, J.P. Tissue engineering: the challenges ahead. Sci. Am. 280, 86, 1999.

2. Hubbell, J.A. Biomaterials in Tissue Engineering. Bio/Technology 13, 565, 1995.

3. Saltzman, W.M. Cell interactions with polymers. In: Lanza, R., Langer, R., and Chick, W., eds. Principles of Tissue Engineering. Austin: Academic Press, R.G. Landes Company, 1997, pp. 225-246.

4. Thomson, R., Yaszemski, M., Powers, J., and Mikos, A. Fabrication of biodegradable polymer scaffolds to engineer trabecular bone. J. Biomater. Sci. Polym. Ed. 7, 23, 1995.

5. Ma, P.X., and Zhang, R. Synthetic nano-scale fibrous extracellular matrix. J. Biomed. Mater. Res. 46, 60, 1999.

6. Ma, P.X., and Langer, R. Degradation, structure and properties of fibrous nonwoven poly(glycolic acid) scaffolds for tissue engineering. In: Mikos, A.G., Leong, K.W., Radomsky, M.L., Tamada, J.A., and Yaszemski, M.J., eds. Polymers in Medicine and Pharmacy. Pittsburgh: MRS, 1995, pp. 99-104.

7. Mikos, A.G., Thorsen, A.J., Czerwonka, L.A., Bao, Y., Langer, R., Winslow, D.N., and Vacanti, J.P. Preparation and characterization of poly(l-lactic acid) foams. Polymer 35, 1068, 1994.

8. Ma, P.X., and Langer, R. Fabrication of biodegradable polymer foams for cell transplantation and tissue engineering. In: Yarmush, M., and Morgan, J., eds. Tissue Engineering Methods and Protocols, Totowa, NJ: Humana Press Inc., 1998, pp. 47-56.

9. Laurencin, C.T., El-Amin, S.F., Ibim, S.E., Willoughby, D.A., Attawia, M., Allcock, H.R., and Ambrosio, A.A. A highly porous 3-dimensional polyphosphazene polymer matrix for skeletal tissue regeneration. J. Biomed. Mater. Res. 30, 133, 1996.

10. Mikos, A., Bao, Y., Cima, L., Ingber, D., Vacanti, J., and Langer, R. Preparation of poly(glycolic acid) bonded fiber structures for cell attachment and transplantation. J. Biomed. Mater. Res. 27, 183, 1993.

11. Mooney, D.J., Baldwin, D.F., Suh, N.P., Vacanti, J.P., and Langer, R. Novel approach to fabricate porous sponges of poly(D,L-lactic-co-glycolic acid) without the use of organic solvents. Biomaterials 17, 1417, 1996.

12. Whang, K., Thomas, C.H., and Healy, K.E. A novel method to fabricate bioabsorbable scaffolds. Polymer 36, 837, 1995. 


\section{SPHERICAL PORE SCAFFOLDS}

13. Park, A., Wu, B., and Griffith, L.G. Integration of surface modification and 3D fabrication techniques to prepare patterned poly(L-lactide) substrates allowing regionally selective cell adhesion. J. Biomater. Sci. Polym. Ed. 9, 89, 1998.

14. Zhang, R., and Ma, P.X. Poly(alpha-hydroxy acids)/hydroxyapatite porous composites for bone tissue engineering: 1. Preparation and morphology. J. Biomed. Mater. Res. 44, 446, 1999.

15. Zhang, R., and Ma, P.X. Porous poly(1-lactic acid)/apatite composites created by biomimetic process. J. Biomed. Mater. Res. 45, 285, 1999.

16. Lo, H., Kadiyala, S., Guggino, S.E., and Leong, K.W. Poly(L-lactic acid) foams with cell seeding and controlledrelease capacity. J. Biomed. Mater. Res. 30, 475, 1996.

17. Athanasiou, K.A., Agrawal, C.M., Barber, F.A., and Burkhart, S.S. Orthopaedic applications for PLA-PGA biodegradable polymers. Arthroscopy 14, 726, 1998.

18. Vacanti, C.A., and Bonassar, L.J. An overview of tissue engineered bone. Clin. Orthopaed. Related Res. 367, (Suppl.), S375, 1999.

19. Freed, L.E., Langer, R., Martin, I., Pellis, N.R., and Vunjak-Novakovic, G. Tissue engineering of cartilage in space. Proc. Natl. Acad. Sci. USA 94, 13885, 1997.

20. Ma, P.X., Schloo, B., Mooney, D., and Langer, R. Development of biomechanical properties and morphogenesis of in vitro tissue engineered cartilage. J. Biomed. Mater. Res. 29, 1587, 1995.

21. Ma, P.X., and Langer, R. Morphology and mechanical function of long-term in vitro engineered cartilage. J. Biomed. Mater. Res. 44, 217, 1999.

22. Cao, Y., Vacanti, J., Ma, X., Paige, K., Upton, J., Chowanski, Z., Schloo, B., Langer, R., and Vacanti, C. Generation of neo-tendon using synthetic polymers seeded with tenocytes. Transpl. Proc. 26, 3390, 1994.

23. Ibarra, C., Jannetta, C., Vacanti, C.A., Cao, Y., Kim, T.H., Upton, J., and Vacanti, J.P. Tissue engineered meniscus: a potential new alternative to allogeneic meniscus transplantation. Transpl. Proc. 29, 986, 1997.

24. Cusick, R.A., Lee, H., Sano, K., Pollok, J.M., Utsunomiya, H., Ma, P.X., Langer, R., and Vacanti, J.P. The effect of donor and recipient age on engraftment of tissue-engineered liver. J. Pediatr. Surg. 32, 357, 1997.

25. Shinoka, T., Ma, P.X., Shum-Tim, D., Breuer, C.K., Cusick, R.A., Zund, G., Langer, R., Vacanti, J.P., and Mayer, J.E., Jr. Tissue-engineered heart valves. Autologous valve leaflet replacement study in a lamb model. Circulation 94, (Suppl.), II, 1996.

26. Shinoka, T., Shum-Tim, D., Ma, P.X., Tanel, R.E., Isogai, N., Langer, R., Vacanti, J.P., and Mayer, J.E., Jr. Creation of viable pulmonary artery autografts through tissue engineering. J. Thorac. Cardiovasc. Surg. 115, 536, 1998.

27. Niklason, L.E., Gao, J., Abbott, W.M., Hirschi, K.K., Houser, S., Marini, R., and Langer, R. Functional arteries grown in vitro. Science 284, 489, 1999.

28. Cao, Y., Vacanti, J.P., Paige, K.T., Upton, J., and Vacanti, C.A. Transplantation of chondrocytes utilizing a polymer-cell construct to produce tissue-engineered cartilage in the shape of a human ear. Plast. Reconstr. Surg. 100, $297,1997$.

29. Ma, P.X., Zhang, R., Xiao, G., and Franceschi, R. Engineering new bone tissue in vitro on highly porous poly(alpha-hydroxyl acids)/hydroxyapatite composite scaffolds. J. Biomed. Mater. Res. 54, 284, 2001.

30. Ishaug-Riley, S.L., Crane-Kruger, G.M., Yaszemski, M.J., and Mikos, A.G. Three-dimensional culture of rat calvarial osteoblasts in porous biodegradable polymers. Biomaterials 19, 1405, 1998.

31. Zhang, R., and Ma, P.X. Synthetic nano-fibrillar extracellular matrices with predesigned macroporous architectures. J. Biomed. Mater. Res. 52, 430, 2000.

32. Reed, J.S. Particle packing characterization. In: Reed, J.S., ed. Principles of Ceramics Processing. New York: John Wiley \& Sons, Inc., 1995, pp. 215-230.

Address reprint requests to: Prof. Peter X. Ma

Department of Biologic and Materials Sciences 1011 North University Ave., Room 2211

The University of Michigan Ann Arbor, MI 48109-1078

E-mail: mapx@umich.edu 


\section{This article has been cited by:}

1. Dr. Xiaoming He , Dr. Hongxu Lu , Dr. Naoki Kawazoe, Prof. Tetsuya Tateishi, Prof. Guoping Chen . A Novel Cylinder-Type PLLA-Collagen Hybrid Sponge for Cartilage Tissue EngineeringA Novel Cylinder-Type PLLA-Collagen Hybrid Sponge for Cartilage Tissue Engineering. Tissue Engineering Part C: Methods 0:ja. . [Abstract] [PDF] [PDF Plus]

2. Kai Zhang, Xuefen Wang, Dazheng Jing, Yin Yang, Meifang Zhu. 2009. Bionic electrospun ultrafine fibrous poly(L-lactic acid) scaffolds with a multi-scale structure. Biomedical Materials 4:3, 035004. [CrossRef]

3. Ville V. Meretoja, Minna Malin, Jukka V. Seppälä, Timo O. Närhi. 2009. Osteoblast response to continuous phase macroporous scaffolds under static and dynamic culture conditions. Journal of Biomedical Materials Research Part A 89A:2, 317-325. [CrossRef]

4. Masaru Tanaka, Masafumi Takebayashi, Masatsugu Shimomura. 2009. Fabrication of Ordered Arrays of Biodegradable Polymer Pincushions Using Self-Organized Honeycomb-Patterned Films. Macromolecular Symposia 279:1, 175-182. [CrossRef]

5. Sung-Wook Choi, Jingwei Xie, Younan Xia. 2009. Chitosan-Based Inverse Opals: Three-Dimensional Scaffolds with Uniform Pore Structures for Cell Culture. Advanced Materials NA-NA. [CrossRef]

6. Kyung Mi Woo, Victor J. Chen, Hong-Moon Jung, Tae-Il Kim, Hong-In Shin, Jeong-Hwa Baek, Hyun-Mo Ryoo, Peter X. Ma . Comparative Evaluation of Nanofibrous Scaffolding for Bone Regeneration in Critical-Size Calvarial DefectsComparative Evaluation of Nanofibrous Scaffolding for Bone Regeneration in Critical-Size Calvarial Defects. Tissue Engineering Part A, ahead of print. [Abstract] [PDF] [PDF Plus]

7. Shih-Jung Liu, Chun-Lien Hsueh, Steve Wen-Neng Ueng, Song-Su Lin, Jan-Kan Chen. 2009. Manufacture of solvent-free polylactic-glycolic acid (PLGA) scaffolds for tissue engineering. Asia-Pacific Journal of Chemical Engineering 4:2, 154-160. [CrossRef]

8. I. O. Smith, X. H. Liu, L. A. Smith, P. X. Ma. 2009. Nanostructured polymer scaffolds for tissue engineering and regenerative medicine. Wiley Interdisciplinary Reviews: Nanomedicine and Nanobiotechnology 1:2, 226-236. [CrossRef]

9. Jinku Kim, Michael J. Yaszemski, Lichun Lu . Three-Dimensional Porous Biodegradable Polymeric Scaffolds Fabricated with Biodegradable Hydrogel PorogensThree-Dimensional Porous Biodegradable Polymeric Scaffolds Fabricated with Biodegradable Hydrogel Porogens. Tissue Engineering Part C: Methods, ahead of print. [Abstract] [PDF] [PDF Plus]

10. Gianluca Ciardelli, Piergiorgio Gentile, Valeria Chiono, Monica Mattioli-Belmonte, Giovanni Vozzi, Niccoletta Barbani, Paolo Giusti. 2009. Enzymatically crosslinked porous composite matrices for bone tissue regeneration. Journal of Biomedical Materials Research Part A 9999A, NA-NA. [CrossRef]

11. Bernadette G. Ilagan, Brian G. Amsden. 2009. Macroporous photocrosslinked elastomer scaffolds containing microposity: Preparation and in vitro degradation properties. Journal of Biomedical Materials Research Part A 9999A, NA-NA. [CrossRef]

12. Haiguang Zhao, Lie Ma, Yihong Gong, Changyou Gao, Jiacong Shen. 2009. A polylactide/fibrin gel composite scaffold for cartilage tissue engineering: fabrication and an in vitro evaluation. Journal of Materials Science: Materials in Medicine 20:1, 135-143. [CrossRef]

13. Jie Meng, Hua Kong, Zhaozhao Han, Chaoying Wang, Guangjin Zhu, Sishen Xie, Haiyan Xu. 2009. Enhancement of nanofibrous scaffold of multiwalled carbon nanotubes/polyurethane composite to the fibroblasts growth and biosynthesis. Journal of Biomedical Materials Research Part A 88A:1, 105-116. [CrossRef] 
14. A. Al-Ahmad, M. Wiedmann-Al-Ahmad, C. Carvalho, M. Lang, M. Follo, G. Braun, A. Wittmer, R. Mülhaupt, E. Hellwig. 2009. Bacterial and Candida albicans adhesion on rapid prototyping-produced $3 \mathrm{D}$-scaffolds manufactured as bone replacement materials. Journal of Biomedical Materials Research Part A 87A:4, 933-943. [CrossRef]

15. Meghan J. Cuddihy , Nicholas A. Kotov . 2008. Poly(lactic-co-glycolic acid) Bone Scaffolds with Inverted Colloidal Crystal GeometryPoly(lactic-co-glycolic acid) Bone Scaffolds with Inverted Colloidal Crystal Geometry. Tissue Engineering Part A 14:10, 1639-1649. [Abstract] [PDF] [PDF Plus]

16. V. Guarino, F. Causa, A. Salerno, L. Ambrosio, P. A. Netti. 2008. Design and manufacture of microporous polymeric materials with hierarchal complex structure for biomedical application. Materials Science and Technology 24:9, 1111-1117. [CrossRef]

17. Peter M. Crapo, Jin Gao, Yadong Wang. 2008. Seamless tubular poly(glycerol sebacate) scaffolds: High-yield fabrication and potential applications. Journal of Biomedical Materials Research Part A 86A:2, 354-363. [CrossRef]

18. Henrik Bäckdahl, Maricris Esguerra, Dick Delbro, Bo Risberg, Paul Gatenholm. 2008. Engineering microporosity in bacterial cellulose scaffolds. Journal of Tissue Engineering and Regenerative Medicine 2:6, 320-330. [CrossRef]

19. Jiashen Li, Xiaoyan Yuan, Fei He, Arthur F. T. Mak. 2008. Hybrid coating of hydroxyapatite and collagen within poly(D,L-lactic- co -glycolic acid) scaffold. Journal of Biomedical Materials Research Part B: Applied Biomaterials 86B:2, 381-388. [CrossRef]

20. Cédryck Vaquette, Céline Frochot, Rachid Rahouadj, Xiong Wang. 2008. An innovative method to obtain porous PLLA scaffolds with highly spherical and interconnected pores. Journal of Biomedical Materials Research Part B: Applied Biomaterials 86B:1, 9-17. [CrossRef]

21. M. Mattioli-Belmonte, G. Vozzi, K. Kyriakidou, E. Pulieri, G. Lucarini, B. Vinci, A. Pugnaloni, G. Biagini, A. Ahluwalia. 2008. Rapid-prototyped and salt-leached PLGA scaffolds condition cell morpho-functional behavior. Journal of Biomedical Materials Research Part A 85A:2, 466-476. [CrossRef]

22. Chi-Hsiung Jou, Wei-Chun Chen, Ming-Chien Yang, Mou-Chen Hwang, Wen-Li Chou, Shang-Ming Lin, Cheng-Yi Hsu. 2008. In vitro biocompatibility of three-dimensional chitosan scaffolds immobilized with chondroitin-6-sulfate. Polymers for Advanced Technologies 19:5, 377-384. [CrossRef]

23. M. Lebourg, R. Sabater Serra, J. Más Estellés, F. Hernández Sánchez, J. L. Gómez Ribelles, J. Suay Antón. 2008. Biodegradable polycaprolactone scaffold with controlled porosity obtained by modified particle-leaching technique. Journal of Materials Science: Materials in Medicine 19:5, 2047-2053. [CrossRef]

24. R. Izquierdo, N. Garcia-Giralt, M.T. Rodriguez, E. Cáceres, S.J. García, J.L. Gómez Ribelles, M. Monleón, Joan C. Monllau, J. Suay. 2008. Biodegradable PCL scaffolds with an interconnected spherical pore network for tissue engineering. Journal of Biomedical Materials Research Part A 85A:1, 25-35. [CrossRef]

25. Musashi Fujishima, Syoei Sakata, Takuya Iwasaki, Kumao Uchida. 2008. Implantable photonic crystal for reflection-based optical sensing of biodegradation. Journal of Materials Science 43:6, 1890-1896. [CrossRef]

26. Jungwoo Lee, Meghan J. Cuddihy, Nicholas A. Kotov . 2008. Three-Dimensional Cell Culture Matrices: State of the ArtThree-Dimensional Cell Culture Matrices: State of the Art. Tissue Engineering Part B: Reviews 14:1, 61-86. [Abstract] [PDF] [PDF Plus] 
27. V. M. Correlo, L. F. Boesel, E. Pinho, A. R. Costa-Pinto, M. L. Alves da Silva, M. Bhattacharya, J. F. Mano, N. M. Neves, R. L. Reis. 2008. Melt-based compression-molded scaffolds from chitosan-polyester blends and composites: Morphology and mechanical properties. Journal of Biomedical Materials Research Part A 9999A, NA-NA. [CrossRef]

28. J. Venugopal, Sharon Low, Aw Tar Choon, S. Ramakrishna. 2008. Interaction of cells and nanofiber scaffolds in tissue engineering. Journal of Biomedical Materials Research Part B: Applied Biomaterials 84B:1, 34-48. [CrossRef]

29. Jorge Más Estellés, Ana Vidaurre, José M. Meseguer Dueñas, Isabel Castilla Cortázar. 2008. Physical characterization of polycaprolactone scaffolds. Journal of Materials Science: Materials in Medicine 19:1, 189-195. [CrossRef]

30. Erhan Pişkin, I. Alper Işoğlu, Nimet Bölgen, Ibrahim Vargel, Sarah Griffiths, Tarık Çavuşoğlu, Petek Korkusuz, Elif Güzel, Sarah Cartmell. 2008. In vivo performance of simvastatin-loaded electrospun spiral-wound polycaprolactone scaffolds in reconstruction of cranial bone defects in the rat model. Journal of Biomedical Materials Research Part A 9999A, NA-NA. [CrossRef]

31. Stéphanie Grenier, Martin Sandig, Kibret Mequanint. 2007. Polyurethane biomaterials for fabricating 3D porous scaffolds and supporting vascular cells. Journal of Biomedical Materials Research Part A 82A:4, 802-809. [CrossRef]

32. V. V. Narulkar, S. Prakash, K. Chandra. 2007. Characteristics of porous zirconia coated with hydroxyapatite as human bones. Bulletin of Materials Science 30:4, 309-314. [CrossRef]

33. Andreas Greiner, Joachim H. Wendorff. 2007. Elektrospinnen: eine faszinierende Methode zur Präparation ultradünner Fasern. Angewandte Chemie 119:30, 5770-5805. [CrossRef]

34. Andreas Greiner, Joachim H. Wendorff. 2007. Electrospinning: A Fascinating Method for the Preparation of Ultrathin Fibers. Angewandte Chemie International Edition 46:30, 5670-5703. [CrossRef]

35. Yihong Gong, Lijuan He, Jun Li, Qingliang Zhou, Zuwei Ma, Changyou Gao, Jiacong Shen. 2007. Hydrogel-filled polylactide porous scaffolds for cartilage tissue engineering. Journal of Biomedical Materials Research Part B: Applied Biomaterials 82B:1, 192-204. [CrossRef]

36. Ying Wan, Ya Fang, Hua Wu, Xiaoying Cao. 2007. Porous polylactide/chitosan scaffolds for tissue engineering. Journal of Biomedical Materials Research Part A 80A:4, 776-789. [CrossRef]

37. Daniel A. Shimko, Eric A. Nauman. 2007. Development and characterization of a porous poly(methyl methacrylate) scaffold with controllable modulus and permeability. Journal of Biomedical Materials Research Part B: Applied Biomaterials 80B:2, 360-369. [CrossRef]

38. Jiashen Li, Audrey Beaussart, Yun Chen, Arthur F.T. Mak. 2007. Transfer of apatite coating from porogens to scaffolds: Uniform apatite coating within porous poly(DL-lactic-co-glycolic acid) scaffoldin vitro. Journal of Biomedical Materials Research Part A 80A:1, 226-233. [CrossRef]

39. K. F. Leong, C. K. Chua, W. S. Gui, Verani. 2006. Building Porous Biopolymeric Microstructures for Controlled Drug Delivery Devices Using Selective Laser Sintering. The International Journal of Advanced Manufacturing Technology 31:5-6, 483-489. [CrossRef]

40. Thomas Weigel, Gregor Schinkel, Andreas Lendlein. 2006. Design and preparation of polymeric scaffolds for tissue engineering. Expert Review of Medical Devices 3:6, 835-851. [CrossRef]

41. Katarzyna Gorna, Sylwester Gogolewski. 2006. Biodegradable porous polyurethane scaffolds for tissue repair and regeneration. Journal of Biomedical Materials Research Part A 79A:1, 128-138. [CrossRef]

42. Yihong Gong, Zuwei Ma, Changyou Gao, Wei Wang, Jiacong Shen. 2006. Specially elaborated thermally induced phase separation to fabricate poly(L-lactic acid) scaffolds with ultra large pores and good interconnectivity. Journal of Applied Polymer Science 101:5, 3336-3342. [CrossRef] 
43. Bradley R. Ringeisen, Christina M. Othon, Jason A. Barron, Daniel Young, Barry J. Spargo. 2006. Jet-based methods to print living cells. Biotechnology Journal 1:9, 930-948. [CrossRef]

44. Thomas Boland, Tao Xu, Brook Damon, Xiaofeng Cui. 2006. Application of inkjet printing to tissue engineering. Biotechnology Journal 1:9, 910-917. [CrossRef]

45. Jayarama Reddy Venugopal, Yanzhong Zhang, Seeram Ramakrishna. 2006. In Vitro Culture of Human Dermal Fibroblasts on Electrospun Polycaprolactone Collagen Nanofibrous Membrane. Artificial Organs 30:6, 440-446. [CrossRef]

46. Ying Yang, Alicia J El Haj. 2006. Biodegradable scaffolds - delivery systems for cell therapies. Expert Opinion on Biological Therapy 6:5, 485-498. [CrossRef]

47. Tatsuya Kitagawa, Tetsuji Yamaoka, Reiko Iwase, Akira Murakami. 2006. Three-dimensional cell seeding and growth in radial-flow perfusion bioreactor for in vitro tissue reconstruction. Biotechnology and Bioengineering 93:5, 947-954. [CrossRef]

48. Jin Gao , Peter M. Crapo , Yadong Wang . 2006. Macroporous Elastomeric Scaffolds with Extensive Micropores for Soft Tissue EngineeringMacroporous Elastomeric Scaffolds with Extensive Micropores for Soft Tissue Engineering. Tissue Engineering 12:4, 917-925. [Abstract] [PDF] [PDF Plus]

49. Manuela E. Gomes, Heidi L. Holtorf, Rui L. Reis, Antonios G. Mikos . 2006. Influence of the Porosity of Starch-Based Fiber Mesh Scaffolds on the Proliferation and Osteogenic Differentiation of Bone Marrow Stromal Cells Cultured in a Flow Perfusion BioreactorInfluence of the Porosity of Starch-Based Fiber Mesh Scaffolds on the Proliferation and Osteogenic Differentiation of Bone Marrow Stromal Cells Cultured in a Flow Perfusion Bioreactor. Tissue Engineering 12:4, 801-809. [Abstract] [PDF] [PDF Plus]

50. Junchuan Zhang, Hong Zhang, Linbo Wu, Jiandong Ding. 2006. Fabrication of three dimensional polymeric scaffolds with spherical pores. Journal of Materials Science 41:6, 1725-1731. [CrossRef]

51. Linbo Wu, Junchuan Zhang, Dianying Jing, Jiandong Ding. 2006. “Wet-state” mechanical properties of three-dimensional polyester porous scaffolds. Journal of Biomedical Materials Research Part A 76A:2, 264-271. [CrossRef]

52. S. Sahoo, H. Ouyang, James C.-H. Goh, T.E. Tay, S.L. Toh. 2006. Characterization of a Novel Polymeric Scaffold for Potential Application in Tendon/Ligament Tissue Engineering. Tissue Engineering, ahead of print060118075515005. [CrossRef]

53. Rajesh Vasita, Dhirendra S Katti. 2006. Nanofibers and their applications in tissue engineering. International Journal of Nanomedicine 1:1, 15-30. [CrossRef]

54. Jungwoo Lee, Sachin Shanbhag, Nicholas A. Kotov. 2006. Inverted colloidal crystals as three-dimensional microenvironments for cellular co-cultures. Journal of Materials Chemistry 16:35, 3558. [CrossRef]

55. S. Sahoo , H. Ouyang, James C.-H. Goh , T.E. Tay , S.L. Toh . 2006. Characterization of a Novel Polymeric Scaffold for Potential Application in Tendon/Ligament Tissue EngineeringCharacterization of a Novel Polymeric Scaffold for Potential Application in Tendon/Ligament Tissue Engineering. Tissue Engineering 12:1, 91-99. [Abstract] [PDF] [PDF Plus]

56. L. Draghi, S. Resta, M. G. Pirozzolo, M. C. Tanzi. 2006. Microspheres leaching for scaffold porosity control. Journal of Materials Science: Materials in Medicine 16:12, 1093-1097. [CrossRef]

57. Shu-Ying Gu, Jie Ren. 2005. Process Optimization and Empirical Modeling for Electrospun Poly(D,L-lactide) Fibers using Response Surface Methodology. Macromolecular Materials and Engineering 290:11, 1097-1105. [CrossRef] 
58. J Venugopal, Y Z Zhang, S Ramakrishna. 2005. Fabrication of modified and functionalized polycaprolactone nanofibre scaffolds for vascular tissue engineering. Nanotechnology 16:10, 2138-2142. [CrossRef]

59. L. M. Mathieu, M.-O. Montjovent, P-E. Bourban, D. P. Pioletti, J.-A. E. Månson. 2005. Bioresorbable composites prepared by supercritical fluid foaming. Journal of Biomedical Materials Research Part A 75A:1, 89-97. [CrossRef]

60. R. B. Diego, M. P. Olmedilla, Á S. Aroca, J. L. G. Ribelles, M. M. Pradas, G. G. Ferrer, M. S. Sánchez. 2005. Acrylic scaffolds with interconnected spherical pores and controlled hydrophilicity for tissue engineering. Journal of Materials Science 40:18, 4881-4887. [CrossRef]

61. R. Brígido Diego, M. Pérez Olmedilla, A. Serrano Aroca, J. L. Gómez Ribelles, M. Monleón Pradas, G. Gallego Ferrer, M. Salmerón Sánchez. 2005. Acrylic scaffolds with interconnected spherical pores and controlled hydrophilicity for tissue engineering. Journal of Materials Science: Materials in Medicine 16:8, 693-698. [CrossRef]

62. Scott J. Hollister. 2005. Porous scaffold design for tissue engineering. Nature Materials 4:7, 518-524. [CrossRef]

63. Xiaohua Liu, Youngjun Won, Peter X. Ma. 2005. Surface modification of interconnected porous scaffolds. Journal of Biomedical Materials Research Part A 74A:1, 84-91. [CrossRef]

64. Linbo Wu , Hong Zhang, Junchuan Zhang, Jiandong Ding . 2005. Fabrication of Three-Dimensional Porous Scaffolds of Complicated Shape for Tissue Engineering. I. Compression Molding Based on Flexible-Rigid Combined MoldFabrication of Three-Dimensional Porous Scaffolds of Complicated Shape for Tissue Engineering. I. Compression Molding Based on Flexible-Rigid Combined Mold. Tissue Engineering 11:7-8, 1105-1114. [Abstract] [PDF] [PDF Plus]

65. J. Venugopal , S. Ramakrishna . 2005. Biocompatible Nanofiber Matrices for the Engineering of a Dermal Substitute for Skin RegenerationBiocompatible Nanofiber Matrices for the Engineering of a Dermal Substitute for Skin Regeneration. Tissue Engineering 11:5-6, 847-854. [Abstract] [PDF] [PDF Plus]

66. C. Guo, P. H. Lin, Y. S. Dong, Y. P. Pu, C. L. Chu. 2005. Novel fabrication method of porous poly(L-lactic acid) scaffolds using liquid?solid extraction. Journal of Materials Science 40:7, 1759-1761. [CrossRef]

67. A. J. Marshall, B. D. Ratner. 2005. Quantitative characterization of sphere-templated porous biomaterials. AIChE Journal 51:4, 1221-1232. [CrossRef]

68. A. N. Stachowiak, A. Bershteyn, E. Tzatzalos, D. J. Irvine. 2005. Bioactive Hydrogels with an Ordered Cellular Structure Combine Interconnected Macroporosity and Robust Mechanical Properties. Advanced Materials 17:4, 399-403. [CrossRef]

69. A.L. Darling, Wei Sun. 2005. Free-form fabrication and micro-CT characterization of poly-/spl epsiv/-caprolactone tissue scaffolds. IEEE Engineering in Medicine and Biology Magazine 24:1, 78-83. [CrossRef]

70. Tejas S. Karande, Joo L. Ong, C. Mauli Agrawal. 2005. Diffusion in Musculoskeletal Tissue Engineering Scaffolds: Design Issues Related to Porosity, Permeability, Architecture, and Nutrient Mixing. Annals of Biomedical Engineering 32:12, 1728-1743. [CrossRef]

71. Edward A. Sander, Alina M. Alb, Eric A. Nauman, Wayne F. Reed, Kay C Dee. 2004. Solvent effects on the microstructure and properties of $75 / 25$ poly(D,L-lactide-co-glycolide) tissue scaffolds. Journal of Biomedical Materials Research 70A:3, 506-513. [CrossRef]

72. A. L. Darling, W. Sun. 2004. 3D microtomographic characterization of precision extruded poly-?-caprolactone scaffolds. Journal of Biomedical Materials Research 70B:2, 311-317. [CrossRef] 
73. Edward A. Botchwey, Solomon R. Pollack, Elliot M. Levine, Eric D. Johnston, Cato T. Laurencin. 2004. Quantitative analysis of three-dimensional fluid flow in rotating bioreactors for tissue engineering. Journal of Biomedical Materials Research 69A:2, 205-215. [CrossRef]

74. Qingpu Hou, Dirk W. Grijpma, Jan Feijen. 2003. Preparation of interconnected highly porous polymeric structures by a replication and freeze-drying process. Journal of Biomedical Materials Research 67B:2, 732-740. [CrossRef]

75. Kyung Mi Woo, Victor J. Chen, Peter X. Ma. 2003. Nano-fibrous scaffolding architecture selectively enhances protein adsorption contributing to cell attachment. Journal of Biomedical Materials Research 67A:2, 531-537. [CrossRef]

76. Zuwei Ma, Changyou Gao, Yihong Gong, Jiacong Shen. 2003. Paraffin spheres as porogen to fabricate poly(L-lactic acid) scaffolds with improved cytocompatibility for cartilage tissue engineering. Journal of Biomedical Materials Research 67B:1, 610-617. [CrossRef]

77. Hui Xu, Yoshinaka Shimizu, Sumito Asai, Kiyoshi Ooya. 2003. Experimental sinus grafting with the use of deproteinized bone particles of different sizes. Clinical Oral Implants Research 14:5, 548-555. [CrossRef]

78. Yuan Lu Cui, Xin Hou, Ai Di Qi, Xiang Hui Wang, Hong Wang, Kai Yong Cai, Yu Ji Yin, Kang De Yao. 2003. Biomimetic surface modification of poly (L-lactic acid) with gelatin and its effects on articular chondrocytesin vitro. Journal of Biomedical Materials Research 66A:4, 770-778. [CrossRef]

79. Jeffrey M. Karp, Kathy Rzeszutek, Molly S. Shoichet, John E. Davies. 2003. Fabrication of Precise Cylindrical Three-Dimensional Tissue Engineering Scaffolds for In Vitro and In Vivo Bone Engineering Applications. Journal of Craniofacial Surgery 14:3, 317-323. [CrossRef]

80. John M. Moran, David Pazzano, Lawrence J. Bonassar . 2003. Characterization of Polylactic Acid-Polyglycolic Acid Composites for Cartilage Tissue EngineeringCharacterization of Polylactic Acid-Polyglycolic Acid Composites for Cartilage Tissue Engineering. Tissue Engineering 9:1, 63-70. [Abstract] [PDF] [PDF Plus]

81. Wan-Ju Li, Cato T. Laurencin, Edward J. Caterson, Rocky S. Tuan, Frank K. Ko. 2002. Electrospun nanofibrous structure: A novel scaffold for tissue engineering. Journal of Biomedical Materials Research 60:4, 613-621. [CrossRef]

82. William L. Murphy, Robert G. Dennis, Joel L. Kileny, David J. Mooney . 2002. Salt Fusion: An Approach to Improve Pore Interconnectivity within Tissue Engineering ScaffoldsSalt Fusion: An Approach to Improve Pore Interconnectivity within Tissue Engineering Scaffolds. Tissue Engineering 8:1, 43-52. [Abstract] [PDF] [PDF Plus]

83. Peter X. Ma, Ruiyun Zhang. 2001. Microtubular architecture of biodegradable polymer scaffolds. Journal of Biomedical Materials Research 56:4, 469-477. [CrossRef] 